\title{
LEITURA E PRODUÇÃO TEXTUAL PARA PREPARAÇÃO AO EXAME CELPE-BRAS: \\ RELATO DE EXPERIÊNCIA DOCENTE NO ENSINO DE PORTUGUÊS COMO LÍNGUA ADICIONAL
}

Ellen Yurika Nagasawa é licencianda em Letras Português/Inglês pela Universidade Federal do Rio Grande do Sul e pesquisadora de Iniciação Científica na área de Linguística Aplicada.

E-mail: ellennagasawa@gmail.com

\begin{abstract}
Resumo
O objetivo deste trabalho é relatar o projeto Leitura e Produção Textual para Preparação ao Exame Celpe-Bras, realizado no Programa de Português para Estrangeiros (PPE-UFRGS). A experiência foi desenvolvida ao longo de oito semanas, tendo os estudantes estrangeiros do Programa de Estudantes ConvênioGraduação (PEC-G) como público-alvo. A sequência didática utilizada foi elaborada com base em pesquisa do acervo do Certificado de Proficiência de Português para Estrangeiros (Celpe-Bras) e teve como principal meta educacional o sucesso na obtenção do certificado do exame pelos participantes. Para tanto, ancorou-se na noção bakhtiniana de gêneros do discurso (BAKHTIN, 2003) e buscou trazer para a sala de aula o trabalho sobre a linguagem e a aprendizagem de formas de participação no mundo social (SIMÕES, 2012).
\end{abstract}

\begin{abstract}
The work aims to narrate the project Reading and Writing for Preparation to the Celpe-Bras Examination, carried through in the Programa de Português para Estrangeiros (PPE-UFRGS). The experience was developed throughout eight weeks, having had the foreign students of the Programa de Estudantes ConvênioGraduação (PEC-G) as subjects. The didactic sequence was elaborated based on the research of the database of Certificado de Proficiência de Português para Estrangeiros (Celpe-Bras) and had as main educational goal the success in the attainment of the certificate of the examination for the participants. For that, it was anchored in the bakhtinian notion of discourse genres (BAKHTIN, 2003) and brought to the classroom the work on language and the learning of forms of participation in the social world (SIMÕES, 2012).
\end{abstract}

Este projeto foi realizado no segundo semestre do ano letivo de 2015, durante meu estágio curricular obrigatório de docência em Língua Portuguesa do curso Licenciatura em Letras, e contou com a participação de onze estudantes estrangeiros do Programa de Português para Estrangeiros (PPE) do Instituto de Letras da Universidade Federal do Rio Grande do Sul (UFRGS).

Para relatar a experiência, o texto organiza-se em cinco seções: primeiramente, discorro sobre os pressupostos teóricos que amparam a proposta pedagógica; na segunda seção, exponho os dados relativos ao contexto do projeto; na terceira, descrevo os procedimentos utilizados na construção da sequência didática; por fim, narro brevemente as aulas na quarta seção. Nas considerações finais do texto, apresento breve reflexão sobre o projeto e o ensino da Língua Portuguesa na área de Português como Língua Adicional (PLA).

\section{1) Pressupostos teóricos}

Levando em consideração minha atuação como bolsista de iniciação científica na área de Linguística Aplicada, meu objeto de pesquisa, o Certificado de Proficiência de Português para Estrangeiros (Celpe-Bras), esteve no eixo central do 
desenvolvimento desta sequência didática aplicada em uma turma de estudantes estrangeiros do Programa de Português para Estrangeiros (PPE).

A visão de linguagem que subjaz à minha proposta de projeto é a de uso da linguagem como ação social (CLARK, 2000), histórica e culturalmente construída, através da qual os sujeitos agem no mundo, participando de diferentes esferas da vida humana. Com esse projeto, portanto, busco, além de levar os estudantes a obterem o certificado de proficiência em Língua Portuguesa, contribuir com a formação de leitores e produtores de textos, capazes de reflexão crítica e participação ativa na sociedade da qual fazem parte, em outras palavras, promover o letramento para a efetiva participação em práticas sociais que envolvam a leitura e a escrita (SCHLATTER, 2009).

O PPE entende que o ensino e a aprendizagem da língua resultam da interação social entre participantes, de maneira coletiva e situada, através de tarefas e projetos pedagógicos ancorados na noção bakhtiniana de gêneros do discurso (KRAEMER, 2012); nessa perspectiva, a sala de aula deve oportunizar a interação entre os participantes e o mundo, por intermédio do uso da linguagem.

Conforme proposto pelos Parâmetros Curriculares Nacionais (BRASIL, 2000) e os Referenciais Curriculares do Rio Grande do Sul (RS, 2009), entendo a aprendizagem como um processo contínuo que se pauta em progressão de competências partindo dos conhecimentos mais próximos dos estudantes rumo aos mais distantes e propiciando a prática do uso-reflexão-uso, ou seja, "do conhecido ao desconhecido e do mais concreto ao mais abstrato" (RS, 2009, p.46).

A progressão, então, é orientada através de sequência didática, conjunto sistemático de tarefas que buscam formar leitores e produtores de textos para através deles possibilitar o acesso às novas práticas de linguagem (DOLZ et al, 2004), não focalizando o ensino em listas de conteúdos de língua e gramática, mas desenvolvendo o planejamento didático com o texto como peça central (SIMÕES, 2012).

\section{2) Contexto}

Durante oito semanas, o projeto foi realizado em uma turma composta por onze estudantes bolsistas do Programa de Estudantes-Convênio de Graduação (PECG), de faixa etária entre 18 e 27 anos. Dentre eles, cinco mulheres e seis homens, oriundos dos seguintes países: Barbados, Benin, Congo, Gabão, Gana e Jamaica.

O PEC-G é um programa do governo brasileiro, criado oficialmente em 1965, que oferece a estudantes de países em desenvolvimento com os quais o Brasil mantém acordo educacional, cultural ou científico-tecnológico a oportunidade de realizar seus estudos de graduação em Instituições de Ensino Superior (IES) brasileiras $^{1}$.

Os estudantes bolsistas chegaram ao Brasil em março de 2015 e, desde então, estudaram português em curso intensivo no PPE com o objetivo principal de obter a

\footnotetext{
${ }^{1}$ FONTE: http://portal.mec.gov.br/pec-g Acesso em 30 Set 2015.
} 
certificação de nível Intermediário na aplicação de outubro do Exame Celpe-Bras, única exigência do governo brasileiro para que possam assumir a vaga na IES que lhes foi concedida.

Além de oferecer cursos de português para falantes de outras línguas, o PPE é um centro de formação de professores no ensino de português como língua adicional e posto aplicador do Exame Celpe-Bras desde sua primeira edição em 1998. O CelpeBras, outorgado pelo Ministério da Educação (MEC), é o único exame oficialmente aceito como reconhecimento de proficiência em Português como Língua Adicional pelo governo brasileiro.

O conceito de proficiência que fundamenta o Exame consiste no "uso adequado da língua para desempenhar ações no mundo" (BRASIL, 2006, p. 3), que, segundo Schoffen (2009, p. 35), é uma proposta de "avaliar a proficiência em Língua Portuguesa não através da medição de conhecimento gramatical ou de conhecimento específico de vocabulário, mas através da capacidade de agir no mundo em situações simulares às reais". O Celpe-Bras, dessa forma, propõe-se a avaliar o potencial do candidato para interagir em português em situações da vida cotidiana e acadêmica no Brasil.

É importante mencionar brevemente o meu trabalho realizado junto ao grupo de pesquisa orientado pela Profa. Dra. Juliana Roquele Schoffen, que foi iniciado com a idealização e a construção do único banco de dados público do Exame CelpeBras (NAGASAWA, 2014), o qual constitui o corpus de pesquisa que tornou possíveis a descrição e a análise das 136 tarefas da Parte Escrita do Exame aplicadas entre 1998 e 2014 (NAGASAWA; SIRIANNI, 2015).

Diante das análises realizadas, foi possível conferir a proposta de natureza comunicativa do exame, que propõe tarefas que se assemelham a situações da vida real com diferentes usos sociais da língua, compondo, assim, um repertório único de multiplicidade de gêneros discursivos que variam conforme os propósitos comunicativos e os interlocutores envolvidos no contexto de comunicação.

Em síntese, o que se pretende frisar com esta exposição é que a compreensão do uso dos gêneros do discurso para aferir a proficiência em língua portuguesa pelo Exame Celpe-Bras foi de imprescindível importância para gerar subsídios ao processo de produção de material didático com vistas à preparação de examinandos por meio de uma perspectiva dialógica da linguagem, segundo a qual nos comunicamos através de tipos relativamente estáveis de enunciados, concretos e únicos, elaborados conforme as especificidades de cada esfera de comunicação (BAKHTIN, 2003).

\section{3) Proposta pedagógica}

Considerando que a prestação do Exame Celpe-Bras constitui uma interlocução pública autêntica e de fundamental importância no momento educacional dos estudantes, configuram-se como metas educacionais a serem alcançadas a realização das provas e o sucesso na obtenção do certificado. Portanto, o Exame torna-se o eixo central no desenvolvimento da sequência didática. Além disso, foi escolhido um gênero discursivo para estruturar o projeto: a carta de leitor. Tal decisão 
deve-se ao fato de este ser um gênero argumentativo, podendo ser de grande utilidade na realização das tarefas da Parte Escrita do Exame.

A Parte Escrita utiliza tarefas integradas de compreensão oral, leitura e produção textual. Segundo o Manual do Candidato, "a tarefa é um convite para agir no mundo, um convite para o uso da linguagem com um propósito social" (BRASIL, 2006, p. 6); assim, as tarefas apresentam um propósito claro de comunicação, bem como relação de interlocução definida, a fim de poder avaliar a adequação do texto à situação comunicativa proposta. Esta parte do exame é composta por quatro tarefas: as duas primeiras avaliam compreensão oral e produção textual, oferecendo um vídeo e um áudio como textos de insumo, dos quais o examinando deve selecionar as informações necessárias para responder ao enunciado; as duas últimas avaliam leitura e produção textual, trazendo um texto escrito como material de insumo.

Desse modo, a sequência didática buscou promover o letramento a partir da circulação social, das funções e dos modos de organização de cartas do leitor; do uso adequado de recursos linguísticos que permitam a argumentação em produção escrita desse gênero; e da prática de habilidades e competências para a realização da Parte Escrita do Exame Celpe-Bras.

Tratou-se de levar o aluno a compreender também a função do gênero carta do leitor inserido como um gênero secundário dentro do gênero discursivo exame de proficiência Celpe-Bras. A sequência didática procurou apenas criar uma situação aproximada das práticas de linguagem que, como corroboram os resultados da pesquisa de iniciação científica, são bastante diversificadas dentro do repertório do Exame, o que impossibilita uma reprodução em situação escolar que corresponda exatamente aos contextos da prova. Além disso, a didatização do gênero evita a repetição sistemática de gêneros discursivos com foco apenas na formatação e não no contexto comunicativo.

$\mathrm{O}$ projeto de aprendizagem visou à proficiência em PLA, entendida como a capacidade de produzir enunciados adequados dentro de determinados gêneros do discurso, configurando a interlocução de maneira adequada ao contexto de produção e ao propósito comunicativo (SCHOFFEN, 2009). Assim sendo, foi elaborada a seguinte proposta nuclear do projeto $^{2}$ :

\begin{tabular}{|l|}
\hline PROPOSTA NUCLEAR \\
\hline Contexto: Exame Celpe-Bras \\
\hline Tema: Uso da tecnologia \\
\hline Problematização: De que maneira utilizamos a tecnologia? \\
\hline Gênero do discurso estruturante: Carta do leitor \\
\hline Outros gêneros do discurso utilizados: Crônica, artigo de opinião, comentário \\
\hline Produto Final: Carta do leitor em resposta à crônica do autor Frei Betto ${ }^{3}$ \\
\hline
\end{tabular}

\footnotetext{
${ }^{2}$ Quadro adaptado de SIMÕES, 2012.

${ }^{3} \mathrm{O}$ enunciado da tarefa realizada pelos estudantes sugere a escrita de uma carta de leitor em resposta à crônica do autor Frei Betto: "Ler jornais e revistas online é um dos seus hábitos. A 'Carta a um jovem
} 
A construção da sequência didática seguiu 10 etapas que incluem a produção inicial e final (DOLZ et al. 2004) e os módulos de atividades preparatórias e de contato inicial ao tema e aos gêneros do discurso utilizando textos autênticos e coerentes com a proposta, que passam por reflexão linguística e pela prática de recursos linguísticos centrada no sentido e não na forma (SCHLATTER, 2009).

Admitindo a diversidade de contextos de ensino e individualidades de estudantes e professores dentro do Brasil e fora dele, proponho dez etapas na elaboração de sequências didáticas que visem o ensino de PLA para a preparação de examinandos à Parte Escrita do Exame Celpe-Bras por meio de gêneros discursivos. A exemplo de Dolz et al. (2004), as etapas são apresentadas em sequência, porém, devem ser adaptadas às necessidades particulares de cada projeto, visando à aquisição das capacidades necessárias ao domínio do gênero estruturante almejado.

As etapas abaixo apresentadas não são de natureza estática e não pretendem ser consideradas como um manual, assumindo, pois, um papel de guia na elaboração de materiais didáticos construídos a partir das necessidades de cada grupo de estudantes que devem ser diagnosticados a partir de observações e de produção textual inicial:

\section{ETAPAS DA SEQUÊNCIA DIDÁTICA}

\begin{tabular}{|c|c|}
\hline 1 & Tarefas de introdução ao tema e ao gênero do discurso estruturante do projeto \\
\hline 2 & Primeira produção textual a partir de um enunciado real do Celpe-Bras \\
\hline 3 & $\begin{array}{l}\text { Tarefas de compreensão de elementos constitutivos nos enunciados das tarefas do } \\
\text { Exame Celpe-Bras (Enunciador(es), Interlocutor(es), Gênero, Propósito(s) e Informações) }\end{array}$ \\
\hline 4 & Tarefas preparatórias para leitura de texto \\
\hline 5 & $\begin{array}{l}\text { Leitura de no mínimo } 3 \text { diferentes exemplares de diferentes suportes do gênero do eixo } \\
\text { central e demais gêneros estruturantes do projeto }\end{array}$ \\
\hline 6 & Tarefas de compreensão global do texto (conteúdo temático) \\
\hline 7 & Tarefas de estudo do texto (estilo e construção composicional) - Reflexão linguística \\
\hline 8 & $\begin{array}{l}\text { Sistematização dos elementos constitutivos do gênero do discurso / Construção dos } \\
\text { descritores avaliativos da produção textual }\end{array}$ \\
\hline 9 & Reescrita (a partir dos descritores de avaliação e feedback) \\
\hline 10 & Avaliação final do texto e possível publicação do produto final \\
\hline
\end{tabular}

A avaliação se deu de diferentes modos no decorrer do projeto; conforme

internauta', publicada na versão eletrônica do Jornal Estado de Minas, chamou a sua atenção por se dirigir ao público internauta. Levando em conta os argumentos apresentados por Frei Betto, escreva para o jornal, emitindo sua opinião sobre a advertência feita pelo autor." Disponível em: https://www.ufrgs.br/acervocelpebras/arquivos/exemplo-prova-de-2011/2010_1 
proposto por Dolz et al. (2004), no início foi realizada a avaliação diagnóstica ${ }^{4}$ a partir de uma primeira produção escrita com o objetivo de estabelecer os conteúdos a serem trabalhados; já no final, a produção textual oportunizou a avaliação somativa ${ }^{5}$ assentada nos critérios elaborados conjuntamente durante o processo de aprendizagem. A construção dos critérios avaliativos foi determinada pelas leituras de exemplares do gênero estruturante e do texto base ao qual a carta do leitor respondia, fundamentandose na concepção de avaliação holística ${ }^{6}$ do Celpe-Bras que fora estabelecida no decorrer do processo, em coerência com os princípios e conceitos que amparam a proposta (SIMÕES et al., 2012).

O produto final foi a reescrita da produção inicial, avaliada pelos próprios estudantes com apoio dos critérios avaliativos (autoavaliação ${ }^{7}$ ) e pela professora $\left(\right.$ feedback $\left.{ }^{8}\right)$ com propósito de possibilitar a aproximação ao nível Intermediário, segundo os parâmetros do Exame. Por fim, foi realizada uma revisão final para a publicação da carta do leitor no site do jornal online.

\section{4) Sumário das aulas}

\section{1) Semana 1}

A observação da turma foi realizada após apresentação do projeto aos estudantes pela coordenadora do curso de extensão. Durante as aulas de observação, foi percebida a ocorrência de momentos de tensão entre estudantes e professores devido ao uso excessivo da internet durante as aulas, através da utilização de celular e notebook por parte de alguns alunos. Esse dado foi importante na escolha da temática do projeto - uso da tecnologia - que foi abordada durante as aulas através de tarefas que incentivaram a reflexão sobre maneiras de se informar através da internet, assunto central da tarefa do Exame escolhida para ser desenvolvida pelos estudantes.

\section{2) Semana 2}

Iniciamos a primeira aula com apresentações pessoais e do cronograma do projeto, seguida da construção do contrato pedagógico. A sequência didática teve início com a atividade de introdução temática (uso da tecnologia) e do gênero estruturante do projeto (carta do leitor) através da leitura e da discussão de Elementos Provocadores da

\footnotetext{
4 “Avaliação diagnóstica, que visa a verificar o que já é conhecido a fím de calibrar o ponto de partida para o ensino de novos conhecimentos"(SCHLATTER;GARCEZ, 2012)

5 “O importante é que o aluno encontre, de maneira explícita, os elementos trabalhados em aula e que devem servir como critérios de avaliação" (DOLZ et al., 2004, p. 107).

6 “A avaliação holística consiste na atribuição de uma única nota para um texto baseada na impressão geral desse texto. Em uma sessão de avaliação holística típica, cada texto é lido rapidamente e então julgado através de uma escala que apresenta os critérios de avaliação." (Weigle, 2002, apud Schoffen, 2009, p. 30).

7 “O olhar do aprendiz sobre o seu próprio processo de aprendizagem” (ANTUNES, 2006, p. 164).

8 "Procedimentos de resposta do professor às produções dos estudantes e as recomendações de novas tarefas para o aluno com base nesses procedimentos" (SCHLATTER; GARCEZ, 2012, p. 167).
} 
Parte Oral do Exame Celpe-Bras ${ }^{9}$ que estimulam a discussão sobre tecnologia e também do levantamento de vocabulário ligado ao tema.

A partir da discussão, iniciou-se a leitura de exemplares de cartas do leitor para debate sobre os elementos constitutivos desse gênero com a construção conjunta de esquema no quadro da sala de aula.

Ao final da primeira aula, os estudantes realizaram a primeira produção escrita resposta à tarefa quatro da primeira edição do Exame de 2010 -, entregue à professora para avaliação diagnóstica, que só retornaria aos estudantes no momento da reescrita, já na parte final do projeto.

\section{3) Semana 3}

Deu-se início às tarefas de compreensão de leitura dos enunciados das tarefas da Parte Escrita do Exame, focando-se na compreensão da interlocução, dos propósitos comunicativos e das informações necessárias do texto base para responder com a escrita do texto. Para isso, lemos, escutamos e assistimos tarefas autênticas do Celpe-Bras, acessíveis através do acervo do Exame. Além disso, os estudantes leram duas páginas do Manual do candidato (2006) que explicam sobre os componentes de avaliação integrada das tarefas.

\section{4) Semana 4}

Demos início às tarefas de pré-leitura de artigo de opinião e comentários sobre o mesmo artigo. As discussões iniciaram-se com as diferenças entre as cartas de leitores conforme o veículo de publicação, incluindo o debate sobre meios de se informar através da internet e sobre blogosfera. A leitura de uma postagem do blogueiro Leonardo Sakamoto e dos comentários em resposta ao texto dele foi seguida de uma dinâmica que visou à reflexão sobre neutralidade e imparcialidade ao informar fatos quando se tem diferentes pontos de vista. A dinâmica, inspirada em Leite e Mendes (2004), é realizada com os estudantes sentados em semicírculo com uma "cena do crime" no centro, uma mesa com diferentes objetos expostos de maneira que, dependendo do lugar onde o estudante estivesse sentado, só era possível visualizar partes dos objetos. Alguns estudantes são chamados a descrever a "cena do crime" da maneira mais neutra e imparcial possível. Os próprios estudantes chegam à conclusão de que todo autor de texto apresenta um diferente ponto de vista sobre o mesmo fato.

Antes do final da aula, os estudantes realizaram tarefas que permitiram mais experiências de leitura de cartas de leitores publicadas em diferentes jornais digitais e que apresentavam diferentes interlocuções e propósitos comunicativos.

\section{5) Semana 5}

Nesta aula, sistematizamos em um quadro os elementos constitutivos dos gêneros carta do leitor e comentário, observando as semelhanças e as diferenças entre os dois gêneros e refletindo sobre o que seria mais apropriado ao Celpe-Bras.

\footnotetext{
${ }^{9}$ PARTE INDIVIDUAL (20 minutos) - "Entrevista e conversa sobre atividades e interesses do candidato e sobre assuntos de interesse geral, a partir de pequenos textos, fotos, cartuns, denominados elementos provocadores" (BRASIL, 2006, p. 8).
} 
Para dar início às reflexões linguísticas, o aspecto a ser trabalhado foi escolhido a partir da primeira produção escrita: discurso reportado. A transposição de discurso direto para discurso indireto com foco no uso do imperfeito do subjuntivo quando o verbo do discurso direto está no imperativo poderia ser utilizada na produção textual dos estudantes, visto que o autor da crônica do texto base da tarefa, Frei Betto, dá vários conselhos ao longo de seu texto com o uso do imperativo. Foi bastante recorrente o uso de citações diretas do texto base na primeira produção dos estudantes, em sua maioria a simples cópia de trechos da crônica. Visto que a avaliação integrada das tarefas da Parte Escrita avalia, também, a compreensão da leitura, no caso da tarefa realizada no projeto, os estudantes precisavam responder o enunciado levando em conta a advertência e os argumentos apresentados por Frei Betto, portanto, reportar o discurso do autor da crônica era importante para alcançar os objetivos do texto.

\section{6) Semana 6}

Nas tarefas de (re)leitura do texto do Frei Betto, os estudantes trabalharam em duplas as atividades de compreensão global do texto. Várias perguntas surgiram e foram sendo respondidas em grupo e individualmente, principalmente em relação a como referenciar o texto base nas respostas do Exame. Ao final das tarefas, tivemos uma revisão do recurso linguístico trabalhado anteriormente: discurso direto/indireto, com mais exercícios de prática e sistematização.

\section{7) Semana 7}

Iniciamos a aula retomando os conhecimentos adquiridos sobre leitura dos enunciados das tarefas do Exame, em especial a tarefa quatro da primeira edição de 2010, "Carta a um jovem internauta", à qual os estudantes responderam como produção inicial e com os elementos do gênero carta de leitor.

Foram realizadas discussões gerais em turma, durante as quais todos fizeram contribuições e anotações. Após essa atividade de retomada, construímos o quadro com os critérios de avaliação do texto, completando as colunas Adequado, Parcialmente Adequado, e Inadequado, conforme o que havíamos acabado de rever sobre o enunciado da tarefa e o gênero do discurso esperado como resposta.

A etapa seguinte foi revisar juntos um texto escrito por um dos estudantes, não identificado e projetado em datashow. Preenchemos juntos o quadro de avaliação do texto, oferecendo sugestões do que melhorar e como melhorar.

A turma, então, foi dividida em três grupos, cada um dos quais recebeu entre três e quatro textos para revisar e preencher os quadros de avaliação. Ao final da aula, cada estudante estava com a sua primeira versão do texto e o quadro de avaliação preenchido para, a partir deles, realizar a reescrita da produção textual.

\section{8) Semana 8}

No início da aula, eles receberam suas reescritas com marcações de revisão linguística na margem dos textos juntamente com um quadro de códigos de revisão. Dessa maneira, foi estimulada aos estudantes a reflexão sobre suas próprias 
inadequações ortográficas, gramaticais e estilísticas, somente sendo solicitada a reescrita de partes das produções textuais.

Com isso, foi finalizado o projeto no laboratório de informática, onde cada estudante digitou sua carta do leitor e enviou como resposta ao texto original do Frei Betto, disponível no Correio Cidadania online.

\section{Conclusão}

A sequência didática e o projeto aqui apresentados buscaram incluir os gêneros do discurso na sala de aula de curso preparatório ao Celpe-Bras, possibilitando a reflexão sobre a perspectiva dialógica de linguagem que permeia as tarefas do Exame e sobre o uso de tecnologia como meio de informação paralelamente à preparação para a realização da prova e o sucesso na obtenção do certificado de proficiência em língua portuguesa.

Assim como Simões (2012, p.42), concluo que o objeto de ensino da aula de português, neste caso PLA, é o trabalho sobre a linguagem e a aprendizagem de formas de participação no mundo social.

\section{Referências}

ACERVO CELPE-BRAS. Disponível em: http://www.ufrgs.br/acervocelpebras.

ANTUNES, I. Avaliação da produção textual no ensino médio. In: BUNZEN, Clécio, MENDONÇA, Márcia (orgs). Português no ensino médio e formação do professor. São Paulo: Parábola, 2006.

BAKHTIN, M. Estética da criação verbal. São Paulo: Martins Fontes, 2003.

BRASIL. Manual do candidato do Exame Celpe-Bras. Brasília, Secretaria de Educação Superior (SESu), MEC, 2006.

CLARK, H. H. O uso da linguagem. In: Cadernos de Tradução $\mathbf{n}^{\circ}$ 9. Porto Alegre: UFRGS, jan-mar 2000. p. 49-71.

DOLZ et al. Seqüências didáticas para o oral e a escrita: apresentação de um procedimento. In: SCHNEWLY, B.; DOLZ J. Gêneros orais e escritos na escola. Campinas: Mercado de Letras, 2004. p. 95-128.

KRAEMER, F. F. Português Língua Adicional: Progressão Curricular com Base em Gêneros do Discurso. Dissertação de Mestrado. Universidade Federal do Rio Grande do Sul, 2012.

LEITE, L. H. A.; MENDES, V. Os projetos de trabalho: um espaço para viver a diversidade e a democracia na escola. In: Projeto - Revista de Educação. $2^{\mathrm{a}}$ ed. Porto Alegre: Projeto, 2004, n.4, jan-jun, p. 25-29.

NAGASAWA, E. Y. Resgatando a história do Exame Celpe-Bras: Construção do banco de dados de provas e documentos públicos do Exame. Trabalho 
apresentado como comunicação no Salão de Iniciação Científica, Universidade Federal do Rio Grande do Sul, 2014.

NAGASAWA, E. Y; SIRIANNI, G. R. Os gêneros do discurso na avaliação de proficiência em português como língua adicional no exame CELPE-BRAS. Trabalho apresentado como pôster no Simpósio Internacional de Estudos de Gêneros Textuais, Universidade de São Paulo, 2015.

SCHLATTER, M. O ensino de leitura em língua estrangeira na escola: uma proposta de letramento. Calidoscópio, São Leopoldo, v. 7, n. 1, p. 11-23, 2009.

SCHLATTER, M; GARCEZ, P. M. Línguas adicionais na escola: aprendizagens colaborativas em inglês. Erechim: Edelbra, 2012.

SCHOFFEN, J. R. Gêneros do discurso e parâmetros de avaliação de proficiência em português como língua estrangeira no exame Celpe-Bras. Tese de Doutorado em Letras. Universidade Federal do Rio Grande do Sul, 2009.

SIMÕES, L. J. et al. Leitura e Autoria: planejamento em Língua Portuguesa e Literatura. Erechim: Edelbra; 2012. 